\title{
Chemokine-driven lymphocyte infiltration: an early intratumoural event determining long-term survival in resectable hepatocellular carcinoma
}

\author{
Valerie Chew, ${ }^{1}$ Jinmiao Chen, ${ }^{1}$ Deming Lee, ${ }^{1}$ Evelyn Loh, ${ }^{1}$ Joyce Lee, ${ }^{2,3}$ \\ Kiat Hon Lim, ${ }^{4}$ Achim Weber, ${ }^{5}$ Ksenija Slankamenac, ${ }^{6}$ Ronnie T P Poon, ${ }^{3,7}$ \\ Henry Yang, ${ }^{1}$ London Lucien P J Ooi, ${ }^{8,9}$ Han Chong Toh, ${ }^{8}$ \\ Mathias Heikenwalder, ${ }^{10,11,12}$ Irene $0 \mathrm{~L} \mathrm{Ng}^{2,3}$ Alessandra Nardin, ${ }^{1}$ \\ Jean-Pierre Abastado ${ }^{1}$
}

- Additional figures and tables are published online only. To view these files please visit the journal online (http://gut.bmj. com/content $/ 61 / 3$.toc

For numbered affiliations see end of article.

\section{Correspondence to Jean-Pierre Abastado, Singapore Immunology Network, BMSI, A*STAR, Immunos \#04-00, 8A Biomedical Grove, Singapore; abastado@immunol.a-star.edu. $\mathrm{sg}$}

Revised 11 August 2011 Accepted 13 August 2011 Published Online First 19 September 2011

\section{ABSTRACT}

Objective Hepatocellular carcinoma (HCC) is

a heterogeneous disease with poor prognosis and limited methods for predicting patient survival. The nature of the immune cells that infiltrate tumours is known to impact clinical outcome. However, the molecular events that regulate this infiltration require further understanding. Here the ability of immune genes expressed in the tumour microenvironment to predict disease progression was investigated.

Methods Using quantitative PCR, the expression of 14 immune genes in resected tumour tissues from 57 Singaporean patients was analysed. The nearesttemplate prediction method was used to derive and test a prognostic signature from this training cohort. The signature was then validated in an independent cohort of 98 patients from Hong Kong and Zurich. Intratumoural components expressing these critical immune genes were identified by in situ labelling. Regulation of these genes was analysed in vitro using the HCC cell line SNU-182

Results The identified 14 immune-gene signature predicts patient survival in both the training cohort $(p=0.0004$ and $H R=5.2)$ and the validation cohort $(p=0.0051$ and $H R=2.5$ ) irrespective of patient ethnicity and disease aetiology. Importantly, it predicts the survival of patients with early disease (stages I and II), for whom classical clinical parameters provide limited information. The lack of predictive power in late disease stages III and IV emphasises that a protective immune microenvironment has to be established early in order to impact disease progression significantly. This signature includes the chemokine genes CXCL10, CCL5 and CCL2, whose expression correlates with markers of $\mathrm{T}$ helper 1 (Th1), $\mathrm{CD}^{+} \mathrm{T}$ and natural killer (NK) cells. Inflammatory cytokines (tumour necrosis factor $\alpha$, interferon $\gamma$ ) and Toll-like receptor 3 ligands stimulate intratumoural production of these chemokines which drive tumour infiltration by $\mathrm{T}$ and NK cells, leading to enhanced cancer cell death.

Conclusion A 14 immune-gene signature, which identifies molecular cues driving tumour infiltration by lymphocytes, accurately predicts survival of patients with HCC especially in early disease.

\section{Significance of this study}

What is already known about this subject?

- Hepatocellular carcinoma (HCC) is a heterogeneous disease with poor prognosis and limited methods for predicting patient survival.

- The nature of the immune cells that infiltrate tumours is known to impact clinical outcome.

- In the past decade, several laboratories used gene expression profiling to define the molecular nature and identify prognostic signatures for HCC. However, little consensus was reached from such efforts and limited attention has so far been paid to the tumour immune microenvironment.

What are the new findings?

- We identified a 14 immune-gene signature predictive of HCC patient survival in both the training cohort from Singapore $(n=57$; $\mathrm{p}=0.0004$ and $\mathrm{HR}=5.2)$ and the validation cohort from Hong Kong and Zurich $(n=98$; $p=0.0051$ and $H R=2.5$ ) irrespective of patient ethnicity and disease aetiology.

- The lack of predictive power in late-stage HCC shows that a protective immune microenvironment has to be established early in order to impact disease progression significantly.

- Inflammatory cytokines (tumour necrosis factor $\alpha$ and interferon $\gamma$ ) and Toll-like receptor 3 ligands stimulate intratumoural production of chemokines especially CXCL10 and CCL5, which drive tumour infiltration by T and natural killer (NK) cells, hence leading to enhanced cancer cell death.

How might it impact on clinical practice in the foreseeable future?

- The ability to make a prognosis in early stages of HCC will help in disease management such as in selection of patients with a better prognosis profile for liver transplantation.

- Improved understanding of the molecular pathways leading to a protective local immune microenvironment will help in the rational design of new therapeutic approaches for patients with HCC. 


\section{INTRODUCTION}

Hepatocellular carcinoma (HCC) claims $>600000$ lives every year worldwide. HCC incidence is rising in Western countries partly due to increased hepatitis $\mathrm{C}$ virus infection. ${ }^{1}{ }^{2}$ Limited treatments are available for patients with advanced disease. Curative resection remains the first line of treatment; however, due to a high recurrence rate, the overall survival of patients with HCC is poor. Sorafenib, a tyrosine kinase inhibitor recently approved for advanced HCC, brings only limited improvement in survival. ${ }^{3}$ More aggressive treatments, including liver transplantation for suitable patients, improve survival. ${ }^{4}$ However, identifying patients with HCC likely to benefit from such approaches remains challenging.

HCC is a heterogeneous disease comprising distinct molecular and clinical subgroups. ${ }^{5}{ }^{6}$ This is largely due to the different HCC aetiologies which include hepatitis, and alcohol- and nonalcohol-induced cirrhosis. Geographical and ethnic variations further contribute to its heterogeneity. ${ }^{7}$ In the past decade, several laboratories used gene expression profiling to define the molecular nature and identify prognostic signatures for HCC. $^{8-12}$ However, little consensus was reached from such efforts, illustrating the complexity and heterogeneity of this cancer. Each study focused on different molecular pathways, and limited attention has so far been paid to the tumour immune microenvironment.

It is now recognised that cancer progression is regulated by both cancer cell-intrinsic and microenvironmental factors. Among the latter, the nature and localisation of immune cells infiltrating the tumour play a central role. While tumour infiltration by myeloid cells is often associated with a poor prognosis, ${ }^{13} 14$ the presence of T helper 1 (Th1) or cytotoxic T cells correlates with a reduced risk of relapse in several cancers. ${ }^{15}$

We previously found that a proinflammatory tumour microenvironment correlates with prolonged survival in a cohort of Singaporean patients with HCC. ${ }^{16}$ In the current study, we identified a 14 immune-gene signature able to predict patient survival from this cohort and validated it in an independent cohort of patients from Hong Kong and Zurich. By combining transcriptome analysis, in situ labelling and in vitro experiments, we identified the cellular sources of the molecules corresponding to the gene signature. This approach revealed (1) a paracrine loop involving CXCL10, Toll-like receptor 3 (TLR3), tumour necrosis factor $\alpha$ (TNF $\alpha$ ), and interferon $\gamma$ (IFN- $\gamma$ ); and (2) an autocrine loop controlling CCL5 production. These two loops shape the immune milieu and recruit a potent antitumoral lymphoid infiltrate to the tumour of patients with longer survival. Our study shows that features derived from the tumour immune microenvironment are of general predictive value irrespective of HCC heterogeneity. Importantly, they determine the clinical outcome of patients with early-stage HCC for whom clinical parameters provide limited survival information. The lack of predictive power in late stages shows, for the first time in HCC, that the protective immune microenvironment has to be established early to promote long-term survival.

\section{MATERIALS AND METHODS \\ Patients}

One hundred and seventy-two resected HCC mRNA samples (one from each patient) were obtained from the National Cancer Centre (NCC), Singapore, Sg ( $n=61$ ), the Queen Mary Hospital $(\mathrm{OMH})$, Hong Kong, HK $(\mathrm{n}=56)$, and the University Hospital Zurich, Switzerland $(n=55)$. All samples were obtained with Ethics Committee approval from patients who underwent curative resection from 1991 to 2009. After censoring patients with poor-quality gene expression profiles, data from Sg patients $(n=57)$ were used as a training cohort to derive and test the survival prediction model, while HK $(n=43)$ and Zurich $(n=55)$ patients were used as an independent validation cohort. A total of 49 paraffin-embedded HCC samples $(\mathrm{Sg}, \mathrm{n}=20$; $\mathrm{HK}, \mathrm{n}=23$; Zurich, $n=6$ ) were obtained for immunohistochemistry or immunofluorescence labelling.

Clinical and demographic characteristics of the training and validation cohorts are summarised in table 1 .

\section{Analysis of gene expression}

Quantitative PCR (qPCR) analysis was performed on a total of 172 resected HCC mRNA samples. Primers were designed using Primer3 and qPCR was performed using iTaq SYBR Green Supermix with ROX (Bio-Rad Laboratories, Berkeley, California, USA), as described previously. ${ }^{16}$ Sixteen immune genes were selected for expression analysis, including the 11 previously published survival-related immune genes and five additional immune genes showing a strong trend of association with prolonged survival. Two of the genes, LTA and CCL22, were omitted from the gene list due to very low/undetectable expression in many of the validation cohorts. The relative gene expression level was calculated by normalisation to the housekeeping gene ACTB using MxPro software (Stratagene, Santa Clara, CA, USA).

Table 1 Comparison of clinical and demographic characteristics of patients with hepatocellular carcinoma in the training (Singapore) and validation (HK+Zurich) cohorts

\begin{tabular}{|c|c|c|c|c|}
\hline Variables & & $\begin{array}{l}\text { Training cohort } \\
(\mathrm{n}=57)\end{array}$ & $\begin{array}{l}\text { Validation cohort } \\
(\mathrm{n}=98)\end{array}$ & p Value \\
\hline Sex, F/M & $\mathrm{n}(\%)$ & $7 / 50(12 / 88)$ & $21 / 77(21 / 79)$ & $\mathrm{NS}^{*}$ \\
\hline Age, years & Median (range) & $59(31-84)$ & $60(20-83)$ & NS† \\
\hline Race, Asian/European & n (\%) & $57 / 0(100 / 0)$ & $46 / 52(47 / 53)$ & $<0.0001^{*}$ \\
\hline Viral status, non-infected/HepB, C, D & $\mathrm{n}(\%)$ & $12 / 43(21 / 75)$ & $32 / 66(33 / 67)$ & NS* \\
\hline Grade, $1+2 / 3+4$ & $\mathrm{n}(\%)$ & $33 / 21(58 / 37)$ & $61 / 24(62 / 24)$ & $N S^{*} \ddagger$ \\
\hline TMN staging, $\mathrm{I} / \mathrm{II}+\mathrm{III}+\mathrm{IV}$ & $\mathrm{n}(\%)$ & $34 / 23(60 / 40)$ & $21 / 77(21 / 79)$ & $<0.0001^{*}$ \\
\hline$\alpha$-Fetoprotein, ng/ml & Median (range) & $19(1.5->70000)$ & $50(1-468600)$ & NS† \\
\hline Tumour size, cm & Median (range) & $6(0.7-23)$ & $5(1.2-23.5)$ & NS† \\
\hline Survival, years & Median (25th/75th \%) & $3.94(0.9 / 5.5)$ & $3.8(1.6 / 7.8)$ & NS§ \\
\hline
\end{tabular}

*Fisher exact test.

†Mann-Whitney.

$\neq$ Good/poor differentiation; different classification system for the HK cohort.

§Kaplan-Meier.

F, female; Hep, hepatitis; HK, Hong Kong; M, male; NS, non-significant. 
A

Training cohort

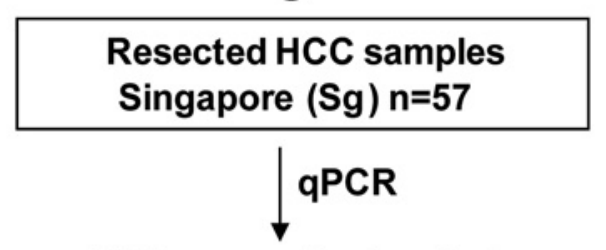

RNA expression level of 16 immune genes

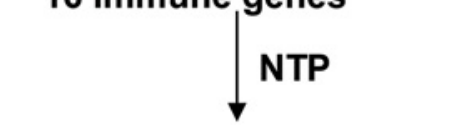

14 IMMUNE-GENE SIGNATURE
Validation cohort

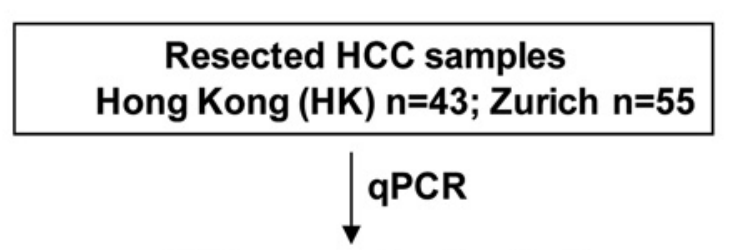

RNA expression level of 14 immune genes

TNF, IL6, CCL2, NCR3, CCR2, TLR4, FCGR1A, CEACAM8, TLR3, CXCL10 CCL5, TBX21, CD8A \& IFNG

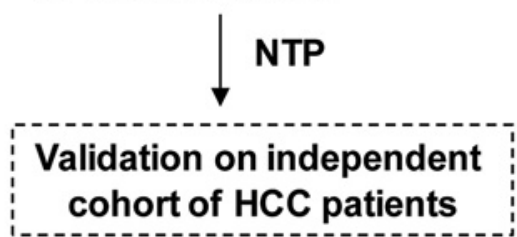

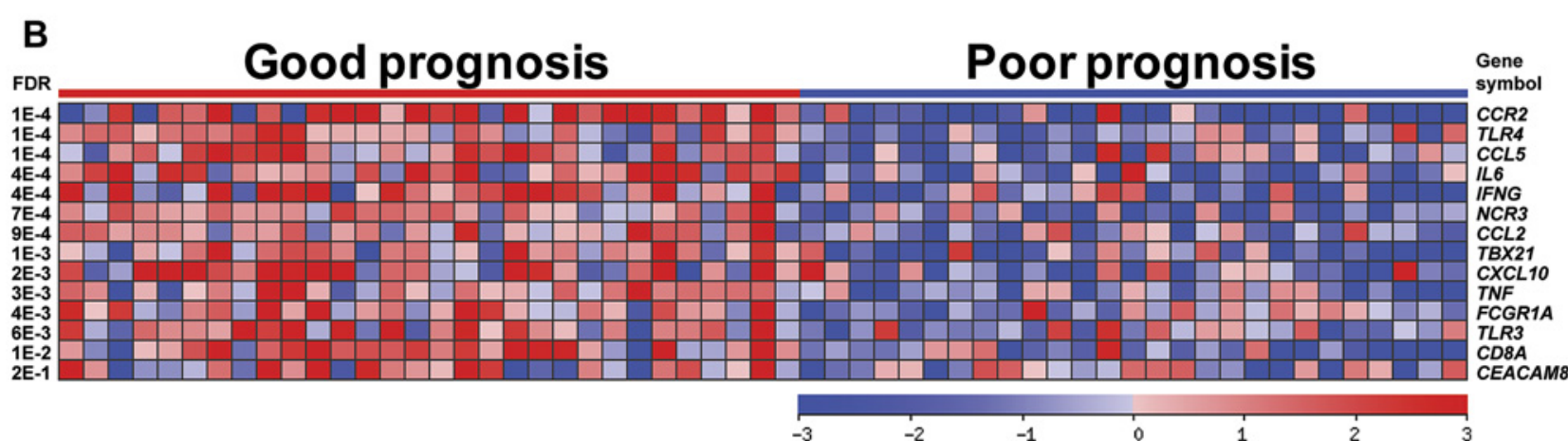

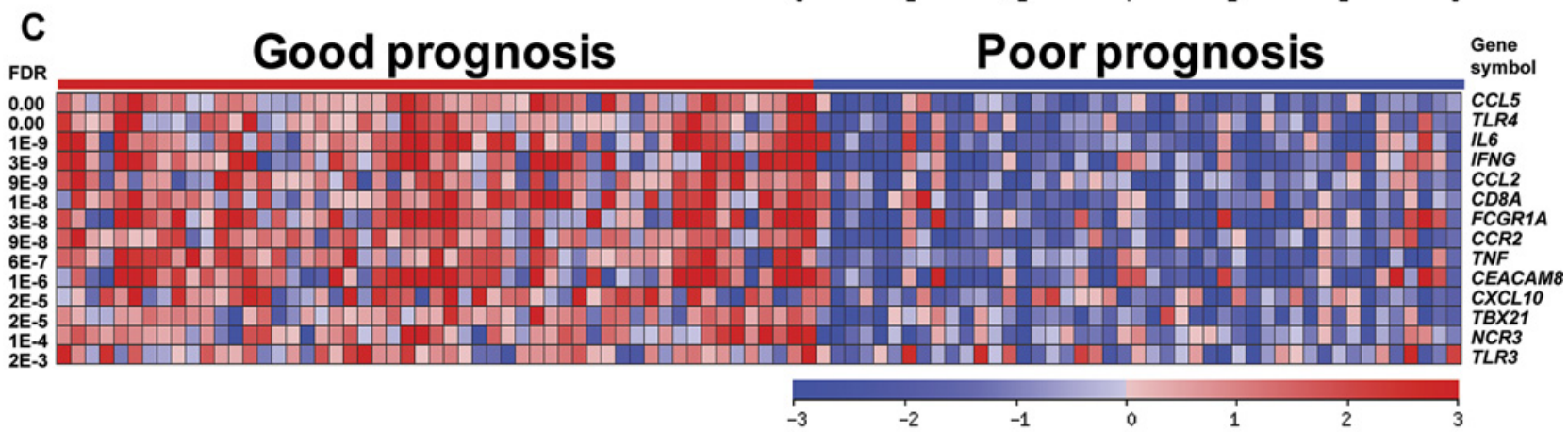

D Training cohort

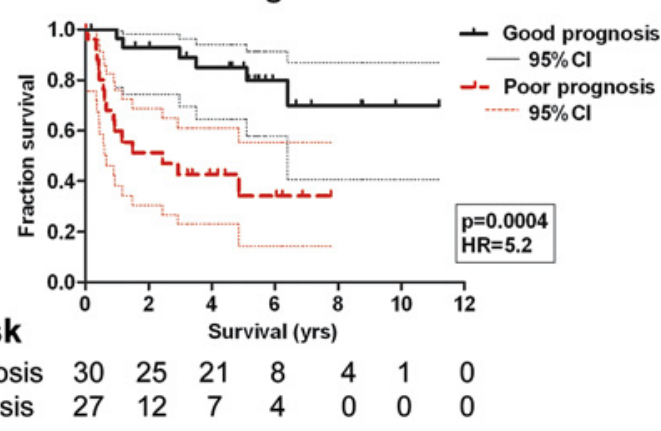

E

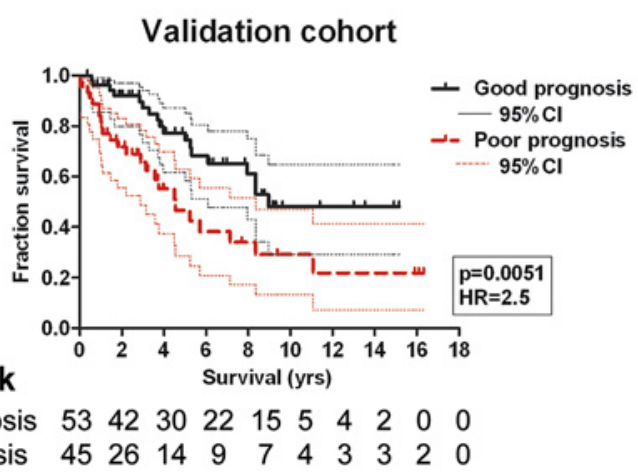

Figure 1 Identification and validation of a 14 immune-gene signature predictive of overall survival in patients with hepatocellular carcinoma (HCC). (A) Study design for the identification of a 14 immune-gene signature derived from the training cohort $(\mathrm{Sg}, \mathrm{n}=57)$ and validated in an independent cohort of patients from HK $(n=43)$ and Zurich $(n=55)$. NTP, nearest-template prediction; qPCR, quantitative PCR. (B and C) Heat maps showing the expression profile of the 14 immune genes (log values) in (B) the training cohort and (C) the validation cohort. Patients are classified as good or poor prognosis according to prediction by the immune-gene signature. FDR, $\mathrm{p}$ value of the test adjusted for false discovery rate (multiple testing). Kaplan-Meier analyses for survival in (D) the training cohort, based on leave-one-out cross-validation testing and in (E) the independent validation cohort. Good and poor prognosis refers to the outcome predicted by the immune signature. $p$, log rank test $p$ value. 


\section{Statistical analyses}

Survival prediction was performed using the nearest-template prediction (NTP) method. The Cox score for each gene, which reflects the correlation between gene expression level and patient survival, was calculated as described previously. ${ }^{10}$ The prognosis prediction for each sample was made based on the proximity of its gene expression level to either of the templates of poor or good prognosis as defined by the vectors of weighted Cox scores. The survival predictor was evaluated in the training cohort $(\mathrm{Sg}$, $\mathrm{n}=57$ ) using a leave-one-out cross-validation, and tested on the independent validation cohort ( $\mathrm{HK}, \mathrm{n}=43$ and Zurich, $\mathrm{n}=55$ ). NTP was also validated by the bootstrap method as described previously. ${ }^{17}$ Two-class differential expression analysis was performed using GEPAS version 4.0 (http://gepas.bioinfo.cipf.es/).

Kaplan-Meier univariate survival analysis was performed using GraphPad Prism. Survival prediction is classified as 'good prognosis' or 'poor prognosis' according to the gene signature or as 'low' or 'high' as compared with the median of the relevant parameters. Patients who are still alive at last follow-up or are deceased due to causes unrelated to HCC were censored. Reported $\mathrm{p}$ values are obtained from the log-rank (Mantel-Cox) test.

Multivariate analysis by the Cox proportional hazards model was used to examine the gene signature in the context of clinical variables.

The NTP method and multivariate analyses were performed with the use of the R statistical package (http://www.r-project.org).

\section{Immunohistochemistry (IHC) and immunofluorescence (IF)}

IHC or IF labelling were performed on paraffin-embedded HCC samples as described before. ${ }^{16}$ The list of primary and secondary antibodies used is given in Supplementary table 1. IHC images were captured with an Olympus DP20 camera attached to a CX31 microscope. For IF, an Olympus FlourView FV1000 confocal microscope was used.

Quantification of positive cells was performed with ImagePro Software from 5-10 random fields at $\times 100$ magnification for IHC, or 10-15 random fields at $\times 200$ magnification for IF. The average value from all quantified fields was determined for each patient. Statistical analysis was performed with GraphPad Prism.

\section{Isolation of tumour-infiltrating leukocytes (TILs)}

Tumour tissues from patients with HCC $(n=3)$ were obtained from Singapore General Hospital with Ethics Committee approval.

Tissues were homogenised using a Dispomix Drive (Xiril AG, Hombrechtikon, Switzerland). Tumour (T) and TILs were separated by a series of low speed centrifugations and filtration through a $100 \mu \mathrm{m}$ filter (Millipore, Santa Clara, CA, USA) to remove large debris. A total of $1 \times 10^{6}$ cells were resuspended in Trizol (Invitrogen, Santa Clara, CA, USA) and RNA was converted to DNA using Taqman Reverse Transcriptase reagent (Applied Biosystems, Foster City, CA, USA) for qPCR analysis. Fraction purity assessed by flow cytometry was $\sim 90 \%$.

\section{In vitro chemokine production and transwell migration assays}

The HCC cell line SNU-182 was obtained from the Korean Cell bank and cultured in complete RPMI medium. Cells were treated with $100 \mathrm{U} / \mathrm{ml}$ IFN $\gamma$ (ImmunoTools, Friesoythe, Germany), $10 \mathrm{ng} / \mathrm{ml} \mathrm{TNF} \boldsymbol{\alpha}, 50 \mu \mathrm{g} / \mathrm{ml}$ poly(I:C) (InvivoGen, SanDiego, CA, USA) or with a combination of IFN $\gamma$ and TNF $\alpha$, or IFN $\gamma$ and poly(I:C). After $24 \mathrm{~h}$, culture supernatants were collected for ELISA and cells were harvested for RNA isolation. RNA isolation, cDNA conversion and qPCR for CXCL10, CCL5 and CCL2 were performed as described above. ELISAs were performed to detect CXCL10, CCL5 and CCL2 using kits from R\&D Systems (CXCL10 and CCL5; R\&D Systems, Inc., Minneapolis, USA) and eBiosciences (CCL2; eBioscience, San Diego, CA, USA) according to the manufacturers' instructions. Absorbance intensity was analysed using a Tecan microplate reader.

For transwell migration assay, SNU-182 cells unstimulated or stimulated with IFN $\gamma$ and poly(I:C) as described above were seeded into 24 -well plates. After $24 \mathrm{~h}, 1 \times 10^{6}$ peripheral blood monocytes (PBMCs) from healthy donors $(n=3)$ untreated or

Table 2 Multivariate analysis of the 14 immune-gene signature

\begin{tabular}{|c|c|c|c|c|}
\hline \multirow[b]{2}{*}{ Variable } & \multicolumn{2}{|c|}{ Univariate analysis $\dagger$} & \multicolumn{2}{|c|}{ Multivariate analysis $\neq$} \\
\hline & HR (95\% Cl) & p Value & HR (95\% Cl) & p Value \\
\hline \multicolumn{5}{|l|}{ Training cohort } \\
\hline \multicolumn{5}{|l|}{ All patients; $n=57$} \\
\hline Immune-gene signature & $4.9(1.9$ to 12.8$)$ & $0.001 *$ & $3.8(1.4$ to 10.1$)$ & $0.008^{*}$ \\
\hline TMN stage (I/II/III) & $2.2(1.4$ to 3.5$)$ & $0.001 *$ & $1.9(1.2$ to 3.0$)$ & $0.010^{*}$ \\
\hline \multicolumn{5}{|l|}{ Validation cohort } \\
\hline \multicolumn{5}{|l|}{ All patients; $\mathrm{n}=98$} \\
\hline Immune-gene signature & $2.3(1.3$ to 4.3$)$ & $0.007^{*}$ & $2.0(1.1$ to 3.8$)$ & $0.032^{*}$ \\
\hline TMN stage (I/II/III/IV) & $1.8(1.2$ to 2.6$)$ & $0.003^{*}$ & $1.6(1.1$ to 2.4$)$ & $0.019^{*}$ \\
\hline \multicolumn{5}{|l|}{ Stage $1 / I I / I I I$ patients; $n=91$} \\
\hline Immune-gene signature & $2.4(1.2$ to 4.7$)$ & $0.009^{*}$ & $2.2(1.1$ to 4.4$)$ & $0.022^{*}$ \\
\hline TMN stage $(\mathrm{I} / \mathrm{II} / \mathrm{III})$ & $1.4(0.9$ to 2.2$)$ & 0.120 & $1.2(0.8$ to 1.9$)$ & 0.331 \\
\hline \multicolumn{5}{|l|}{ Training + validation cohort } \\
\hline \multicolumn{5}{|l|}{ All patients; $n=155$} \\
\hline Immune gene signature & $3.0(1.8$ to 5.1$)$ & $2.18 \mathrm{E}-05$ & 2.7 (1.4 to 5.2$)$ & $0.004^{*}$ \\
\hline Grade $(1 / 2 / 3 / 4)$ & $1.4(0.9$ to 2.0$)$ & 0.137 & $1.4(0.9$ to 2.4$)$ & 0.157 \\
\hline TMN stage (I/II/III/IV) & $1.8(1.4$ to 2.4$)$ & $2.14 \mathrm{E}-05$ & $1.8(1.2$ to 2.8$)$ & $0.005^{*}$ \\
\hline Tumour size $(<$ median/ $\geq$ median) & $1.4(0.8$ to 2.5$)$ & 0.253 & $0.6(0.3$ to 1.2$)$ & 0.158 \\
\hline AFP $(<$ median $/ \geq$ median) & $1.4(0.8$ to 2.3$)$ & 0.207 & $1.2(0.6$ to 2.2$)$ & 0.649 \\
\hline Age (<median/ $\geq$ median) & $1.4(0.8$ to 2.2$)$ & 0.236 & $1.6(0.9$ to 3.0$)$ & 0.144 \\
\hline
\end{tabular}

Median values: tumour size $=5.4 \mathrm{~cm}$; $\alpha$-fetoprotein $(\mathrm{AFP})=25 \mathrm{ng} / \mathrm{ml}$; age $=60$.

*Significant $(\mathrm{p}<0.05)$

†Univariate analysis, Cox proportional hazard regression.

$\ddagger$ Multivariate analysis, Cox proportional hazard regression. 
pretreated with anti-CXCR3 $(25 \mu \mathrm{g} / \mathrm{ml}$; clone 1C6, BD Pharmingen) or anti-CCR5 $(10 \mu \mathrm{g} / \mathrm{ml}$; clone 2D7, BD Pharmingen, San Diego, CA, USA) neutralising antibodies at $37^{\circ} \mathrm{C}$ for $1.5 \mathrm{~h}$ were added onto the transwell filter inserts $(3 \mu \mathrm{m}$ pore size, $\mathrm{BD}$ Falcon, San Diego, CA, USA). Transmigration was assessed after $3 \mathrm{~h}$.

\section{RESULTS}

Identification and validation of an immune-gene signature predicting overall survival of patients with HCC

We previously characterised the expression profile of 49 immunerelated genes in 61 resected HCC tumour samples from Singapore, and found 11 immune genes whose expression was associated with superior patient survival. ${ }^{16}$ In the current study, we analysed the RNA expression of 14 immune genes: TNF, IL6, CCL2, NCR3, CCR2, TLR4, FCGR1A, CEACAM8, TLR3, CXCL10,
CCL5, TBX21, CD8A and IFNG. We used NTP to identify and cross-validate (by the leave-one-out method) a 14 immune-gene signature predictive of overall survival in 57 Singaporean patients with resectable HCC (as a training cohort). The NTP method was chosen because it allows independent prediction for each sample and is less sensitive to differences in sample processing and analysis. ${ }^{18}$ The signature was then validated in an independent cohort of patients from Hong Kong $(n=43)$ and Zurich $(\mathrm{n}=55)$ (figure $1 \mathrm{~A}$ ). Bootstrapping analysis also showed similar results (Supplementary figure 1).

In general, the 14 immune genes display higher expression in patients with good prognosis in both the training (figure 1B) and the validation cohort (figure $1 \mathrm{C}$ ). The relative importance of each gene was assessed using its Cox score (Supplementary table 1). Despite the differences in patient ethnicity and disease stage (table 1), the herein presented 14-gene signature accurately
Figure 2 Superior prognostic power of the 14 immune-gene signature compared with clinical parameters. Kaplan-Meier analyses for survival of (A) stage I patients ( $n=55$, training and validation cohort) according to the immune-gene signature accurately predicts patient survival; (B) stage I patients according to grade $(n=50)$; (C) stage II patients ( $n=46$, training and validation cohort) according to the immune gene signature accurately predicts patient survival and (D) stage II patients according to grade $(n=45)$. $p$, log rank test $p$ value. (E) The plot shows HRs with $95 \% \mathrm{Cl}$ for subgroups of patients according to clinical and demographic characteristics. Age, median=61; AFP conc ( $\alpha$-fetoprotein concentration), median $=20 \mathrm{ng} / \mathrm{ml}$; tumour size, median $=4.3 \mathrm{~cm}$.
A

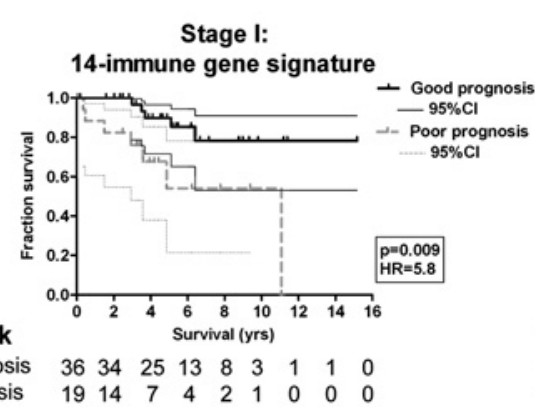

No. at Ris

Good prognosis Poor prognosis

C

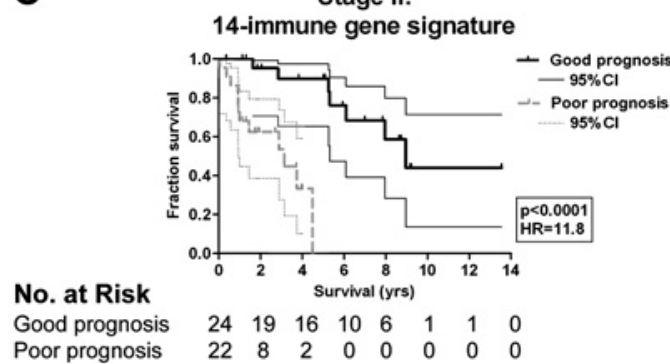

B

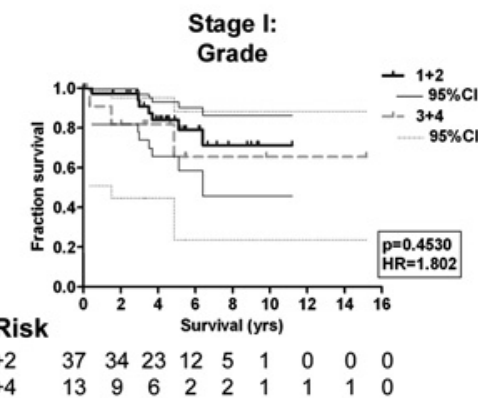

Grade 3+4

D

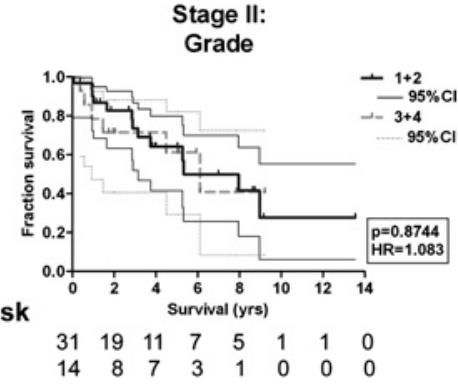

E

Hazard Ratio (95\% Cl)

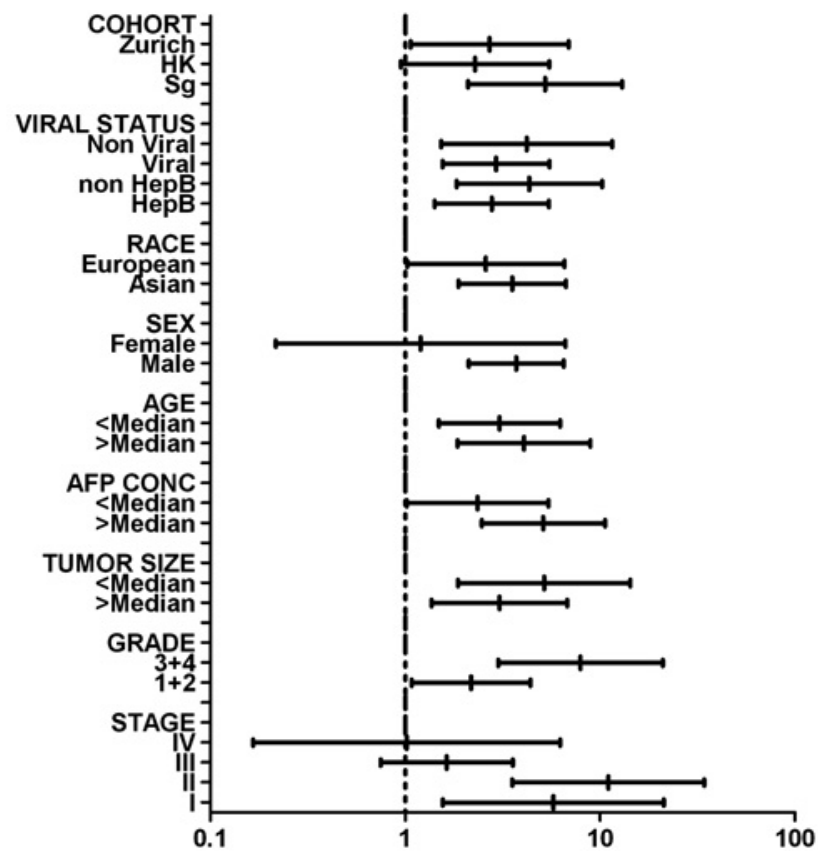


A

CXCL10

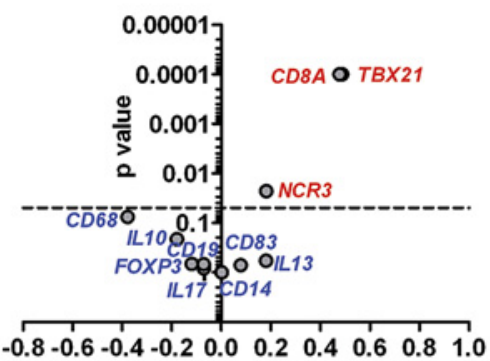

Pearson $r$

B

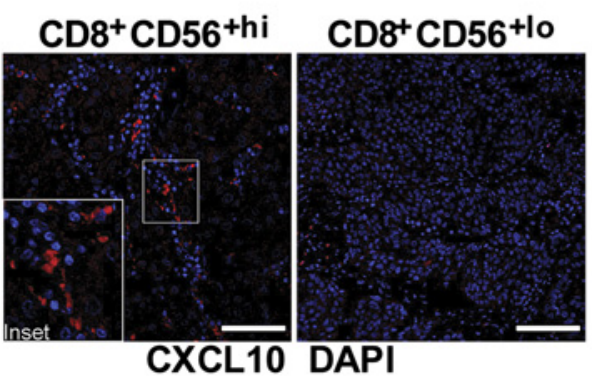

CCL5

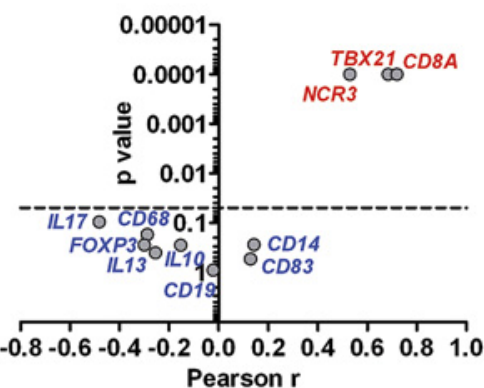

C
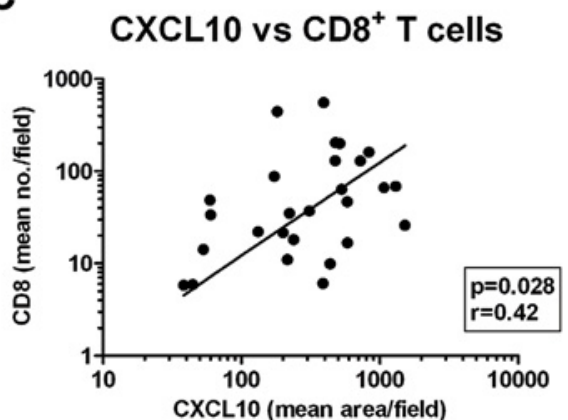

CCL2

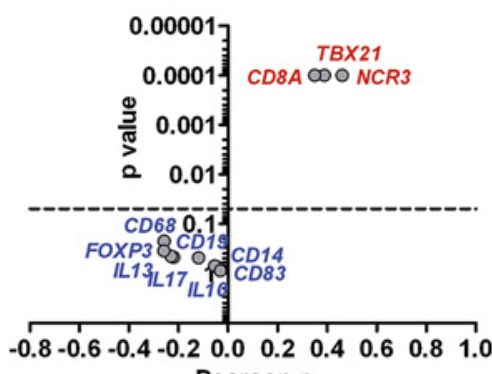

Pearson $r$

CXCL10 vs $\mathrm{CD}^{+}{ }^{+} \mathrm{T}$ cells

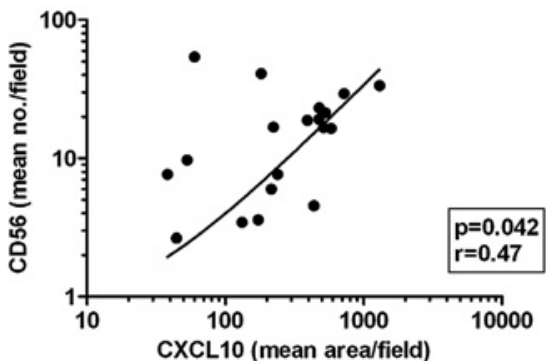

Figure 3 CXCL10, CCL5 and CCL2 expression correlates with tumour infiltration by T and natural killer (NK) cells. (A) In patients with hepatocellular carcinoma (HCC; training and validation cohort, $\mathrm{n}=172$ ), CXCL10, CCL5 and CCL2 RNA positively correlate with TBX21, CD8A and NCR3 (marked in red) but not with CD14, CD68, CD19, CD83, IL13, IL17, FOXP3 or IL10 (marked in blue). Graphs show p values against Pearson correlation coefficients r. The dotted line shows the limit of significance $(p<0.05)$. (B) Representative immunofluorescence images showing higher density of CXCL10expressing cells (red) in a tumour sample with high (left) versus low (right) density of infiltrating CD8 ${ }^{+}$and $\mathrm{CD}^{2} 6^{+}$cells as quantified by immunohistochemistry $(\mathrm{IHC})$. The area in the rectangle is magnified in the left inset. Bar $=50 \mu \mathrm{m} ; \times 400$ magnification. (C) Correlation of CXCL10 protein expression with the density of $\mathrm{CD}^{+}$(left) and $\mathrm{CD}^{+} 6^{+}$(right) immune cells. CXCL10 expression was determined by quantification of the CXCL10-labelled area, and CD8 ${ }^{+}$and $\mathrm{CD} 6^{+}$cell densities were measured by IHC in tumour fields of patient samples (CD8 ${ }^{+}, \mathrm{n}=27 ; \mathrm{CD} 56^{+}, \mathrm{n}=19$, training and validation cohort). $p$ Values and correlation coefficients ( $r$ ) were calculated using the Spearman correlation test. DAPI, 4',6-diamidino-2phenylindole.

A

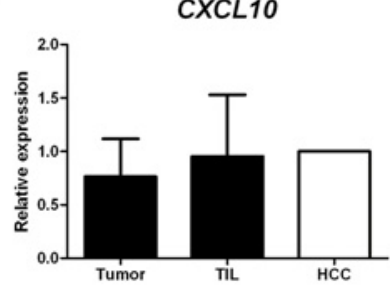

CCL5

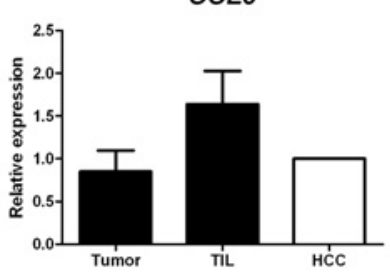

CCL2

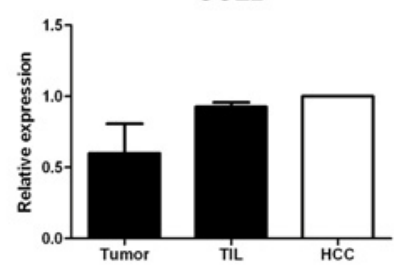

B

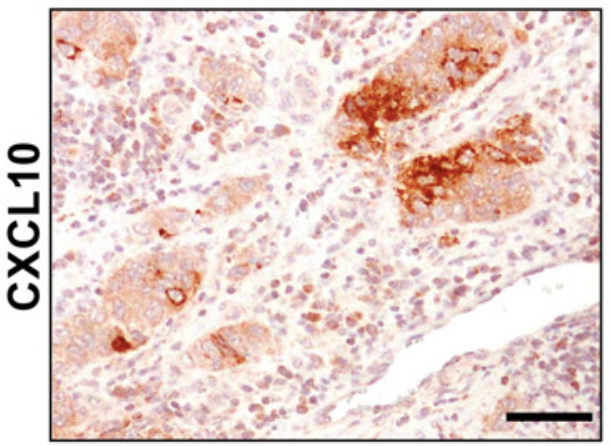

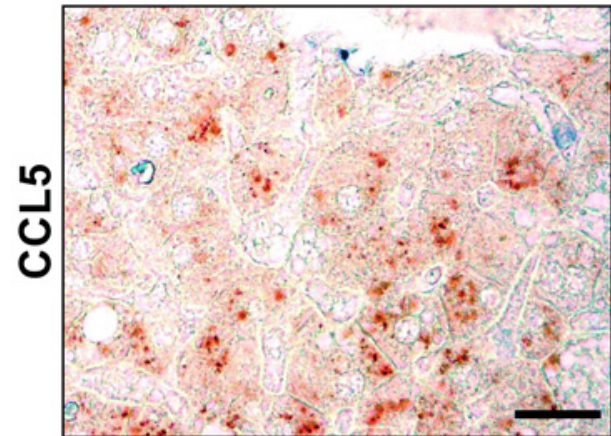

Figure 4 CXCL10, CCL5 and CCL2 are produced by both immune and cancer cells within hepatocellular carcinoma (HCC) tumours. (A) Quantitative PCR (qPCR) analysis of CXCL10, CCL5 and CCL2 RNA expression in purified tumour cells (Tumour), tumour-infiltrating leucocytes (TIL) and unfractionated HCC nodules (HCC) from freshly resected tumours. The chemokines are expressed in all three compartments. Graphs show means and SD normalised to Tumour. (B) Representative immunohistochemistry images of CXCL10 (left) and CCL5 (right) showing expression in cells with cancer cell morphology. Bar $=50 \mu \mathrm{m} ; \times 200$ magnification. (C) Representative immunofluorescence (IF) images showing co-localisation of CXCL10 (red) and CD68 (green). Bar $=20 \mu \mathrm{m} ; \times 800$ magnification. (D) Representative IF images showing co-localisation of CCL5 (red) with either CD68 or CD3 (green). Bar $=20 \mu \mathrm{m} ; \times 800$ magnification. DAPI, 4',6-diamidino-2-phenylindole. 


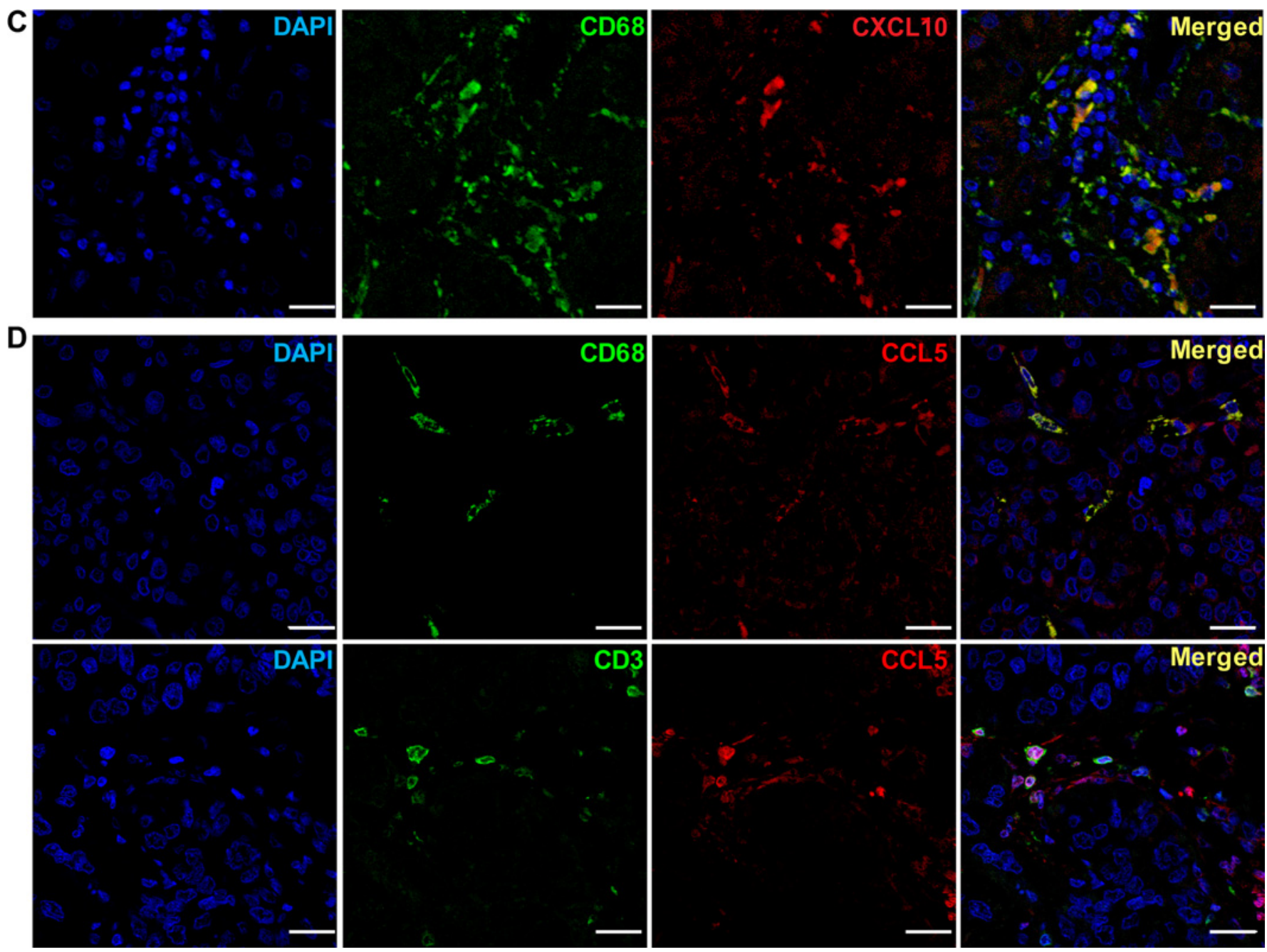

Figure 4 Continued.

predicts patient survival in both the training cohort $(p=0.0004$ and $H R=5.2$; figure $1 D)$ and the validation cohort $(p=0.0051$ and $\mathrm{HR}=2.5$; figure $1 \mathrm{E}$ ). Multivariate analysis showed that this gene signature is an independent predictor of survival together with stage when six parameters are analysed (table 2). Strikingly, when stage IV patients were excluded, the immune signature was the only predictor of survival (table 2).

\section{Superior predictive power of the 14 immune-gene signature in early-stage patients}

In the Singapore cohort, $60 \%$ of patients presented with stage I disease at diagnosis (table 1). We therefore measured the performance of the identified immune signature in patients with early (stages I and II) disease and compared it with clinical parameters generally used for prognosis of such patients. First, we noted that stage I $(n=55)$ and II $(n=46)$ patients (from both the training and validation cohorts) present a wide range of survival times, from a few months to $>15$ years (Supplementary figure 2). The immune signature accurately predicted the overall survival of these patients in Kaplan-Meier analyses (stage I, $\mathrm{p}=0.009, \mathrm{HR}=5.8$; stage II, $\mathrm{p}<0.0001, \mathrm{HR}=11.8$ ) (figure $2 \mathrm{~A}, \mathrm{C}$ ). In contrast, clinical parameters such as grade (figure $2 B, D$ ), serum $\alpha$-fetoprotein (AFP) concentration or tumour size (Supplementary figure 2) did not predict overall survival of these patients. Similar results were obtained from bootstrapping analysis (Supplementary figure 1).
The predictive power of the 14-gene signature was also tested in various subgroups of patients (figure 2E). Interestingly, it did not predict the survival of stage III or IV patients. Therefore, the immune signature allows a robust and reliable prediction of overall survival in patients with early HCC for whom classical clinical parameters are not significant.

\section{CXCL10, CCL5 and CCL2 expression correlates with} intratumoural infiltration of Th1, $\mathrm{CDB}^{+} \mathrm{T}$ and NK cells

Chemokine and chemokine receptor genes such as CXCL10, CCL5, CCL2 and CCR2 constitute a prominent group in the immune signature identified. Since chemokines are critical for attracting immune cells, ${ }^{19}$ we predicted that expression of these chemokines would correlate with tumour infiltration by defined immune cell subsets. To investigate this, we searched for correlations at the transcriptional level in 172 patient samples from both the training and validation cohorts. RNA expression of CXCL10, CCL5 and CCL2 correlated with markers of Th1 cells (TBX21), $\mathrm{CD}^{+} \mathrm{T}(C D 8 A)$ and NK (NCR3) cells (marked in red, figure $3 \mathrm{~A})$. Interestingly, $T B X 21, C D 8 A$ and $N C R 3$ are also among the genes present in the signature. There was no correlation between expression of these chemokines and markers of other immune cell subsets such as macrophages (CD14 and CD68), Th2 (IL13), Th17 (IL17), Treg (FoxP3 and IL10), B (CD19) or dendritic (CD83) cells (marked in blue, figure $3 \mathrm{~A})$. This shows that CXCL10, CCL5 and CCL2 are associated with, and likely to 
A

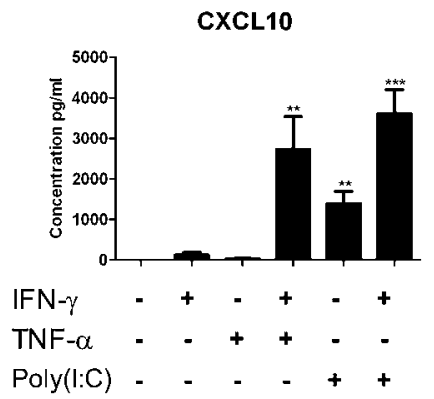

D

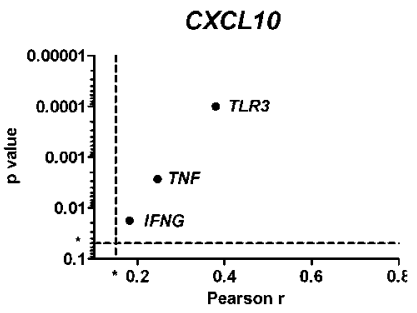

B

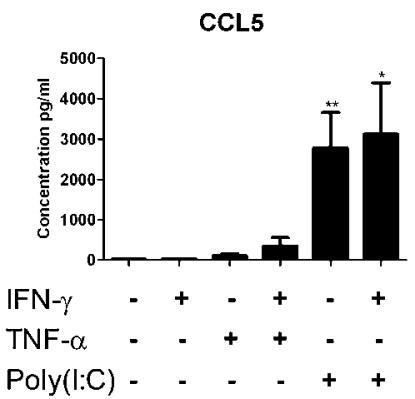

C

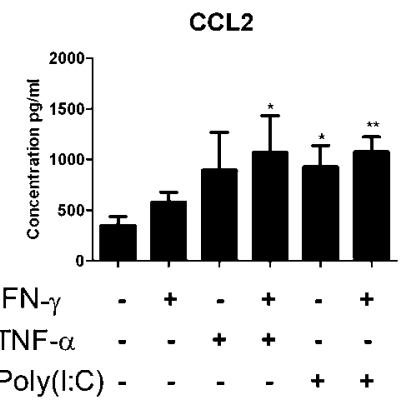

E
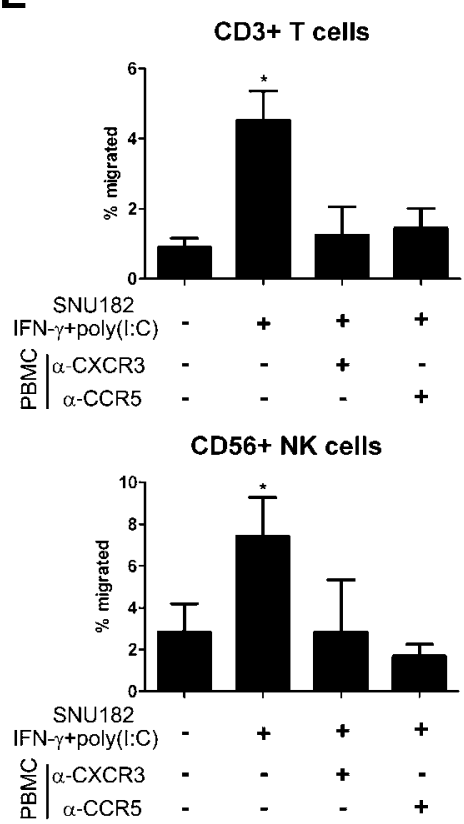

Figure 5 The production of CXCL10, CCL5 and CCL2 by HCC cell lines is induced by interferon $\gamma$ (IFN $\gamma$ ), tumour necrosis factor $\alpha$ (TNF $\alpha$ ) and Toll-like receptor 3 (TLR3) ligands. ELISA for (A) CXCL10, (B) CCL5 and (C) CCL2 concentration in culture supernatants from the SNU-182 hepatocellular carcinoma (HCC) cell line $24 \mathrm{~h}$ after stimulation with IFN $\gamma, \mathrm{TNF} \alpha$ and/or poly(l:C). Two-tailed Student unpaired t test; ${ }^{*} \mathrm{p}<0.05 ;{ }^{* *} \mathrm{p}<0.01 ;{ }^{* * *} \mathrm{p}<0.001$ compared with unstimulated control. Graphs show the means and SD from three independent experiments. (D) CXCL10, CCL5 and CCL2 RNA are positively correlated with IFNG, TNF and TLR3 in patients with HCC (training and validation cohort, $\mathrm{n}=172$ ). Graphs show the $\mathrm{p}$ value against Pearson correlation coefficients $r$. Dotted lines show limits of significance for $r(r=0.15)$ and $p(p=0.05)$. (E) Transmigration assay with peripheral blood mononuclear cells (PBMCs) isolated from healthy donors $(n=3)$ towards unstimulated or stimulated SNU-182 cells with IFN $\gamma$ and poly(l:C) $24 \mathrm{~h}$ prior to transmigration. In blocking experiments, PBMCs were pretreated with anti-CXCR3 or anti-CCR5 neutralising antibodies at $37^{\circ} \mathrm{C}$ for $1.5 \mathrm{~h}$. Graphs show means and SEM. $p$ Values were calculated using paired $t$ test against basal transmigration towards unstimulated $\mathrm{HCC}$. ${ }^{*} \mathrm{p}<0.05$. NK, natural killer.

attract specifically, Th1, $\mathrm{CD}^{+} \mathrm{T}$ and $\mathrm{NK}$ cells into $\mathrm{HCC}$ tumours.

To support this further, we measured the surface expression of CXCR3, CCR5 and CCR2 (the main receptors for CXCL10, CCL5 and CCL2, respectively) on PBMCs from healthy donors and patients with HCC, as well as on infiltrating leucocytes isolated from freshly resected tumours (TILs) or adjacent nontumoural tissues (non-tumour-infiltrating lymphocytes or NILs). Flow cytometry analysis showed that T and NK cells represent the majority of the immune subsets expressing CXCR3 and CCR5 (Supplementary figure 3A). Furthermore, a greater percentage of $\mathrm{T}$ and $\mathrm{NK}$ cells express CCR 5 and CCR2 in the PBMCs, TILs and NILs of patients as compared with healthy donor PBMCs (Supplementary figure 3A). This observation may indicate an increased propensity of $\mathrm{T}$ and NK cells from HCC patients to be attracted by CCL5 and CCL2.

We also analysed CXCL10 expression in tumour sections using IF. We first verified that CXCL10-specific IF correlated with mRNA expression (Supplementary figure 3B). We next showed that higher CXCL10-specific IF (figure 3B) was observed in samples with a higher density of $\mathrm{CD}^{+}{ }^{+}$and $\mathrm{CD} 6^{+}$ cells, as determined by IHC. Further quantification showed that the CXCL10 IF correlated with the density of $\mathrm{CD}^{+} \mathrm{T}$ cells and $\mathrm{CD}^{+} 6^{+} \mathrm{NK}$ cells (CD8, $\mathrm{n}=27, \mathrm{p}=0.028, \mathrm{r}=0.42$; and CD56, $\mathrm{n}=19, \mathrm{p}=0.042, \mathrm{r}=0.47$ ) (figure $3 \mathrm{C}$ ) and also with patient survival $(\mathrm{n}=25, \mathrm{p}=0.024, \mathrm{HR}=3.5$ ) (Supplementary figure $3 \mathrm{C}$ ).

Taken together, these data strongly suggest that CXCL10, CCL 5 and CCL2 are the main chemokines attracting Th1 T cells, $\mathrm{CD}^{+} \mathrm{T}$ cells and NK cells into the tumour microenvironment.

\section{Chemokines associated with patient survival are produced by both cancer cells and TILs}

To understand the molecular interactions taking place within the tumour, we sought to identify the source of CXCL10, CCL5 and CCL2 within HCC. Single-cell suspensions from fresh tumour samples were separated into tumour cells and TILs, followed by chemokine expression analysis using qPCR. The three chemokine genes were transcribed in both tumour cells and TILs (figure 4A). Furthermore, when CXCL10 and CCL5 expression was analysed in situ by IHC, many chemokineproducing cells exhibited cancer cell morphology (figure 4B). CXCL10 was also expressed by TILs. IF on tumour sections, combining labelling for CXCL10 and immune cell markers (CD68, CD3 and CD20), revealed that most of the CXCL10producing immune cells co-expressed CD68 (figure 4C) but not T or B cell markers (data not shown). Similarly, we found colocalisation of CCL5 and CD68 (figure 4D). Hence, macrophages within HCC tumours express both CXCL10 and CCL5.

Besides macrophages, CCL5 was also produced by $\mathrm{CD}^{+} \mathrm{T}$ cells (figure 4D). Given the ability of CCL5 to attract T cells, this suggests an autocrine loop in which CCL5 produced by macrophages and/or cancer cells attracts $T$ cells, which produce more CCL5 to amplify $T$ cell infiltration further.

TNF $\alpha$, IFN $\gamma$ and TLR3 ligands induce expression of CXCL10, CCL5 and CCL2 by HCC cells and induce transmigration of $T$ and NK cells

TNF $\alpha$, IFN $\gamma$ and TLR agonists stimulate CXCL10, CCL2 and CCL5 secretion by monocytes/macrophages, ${ }^{20-22}$ but little is known about the regulation of these chemokines in cancer cells. 

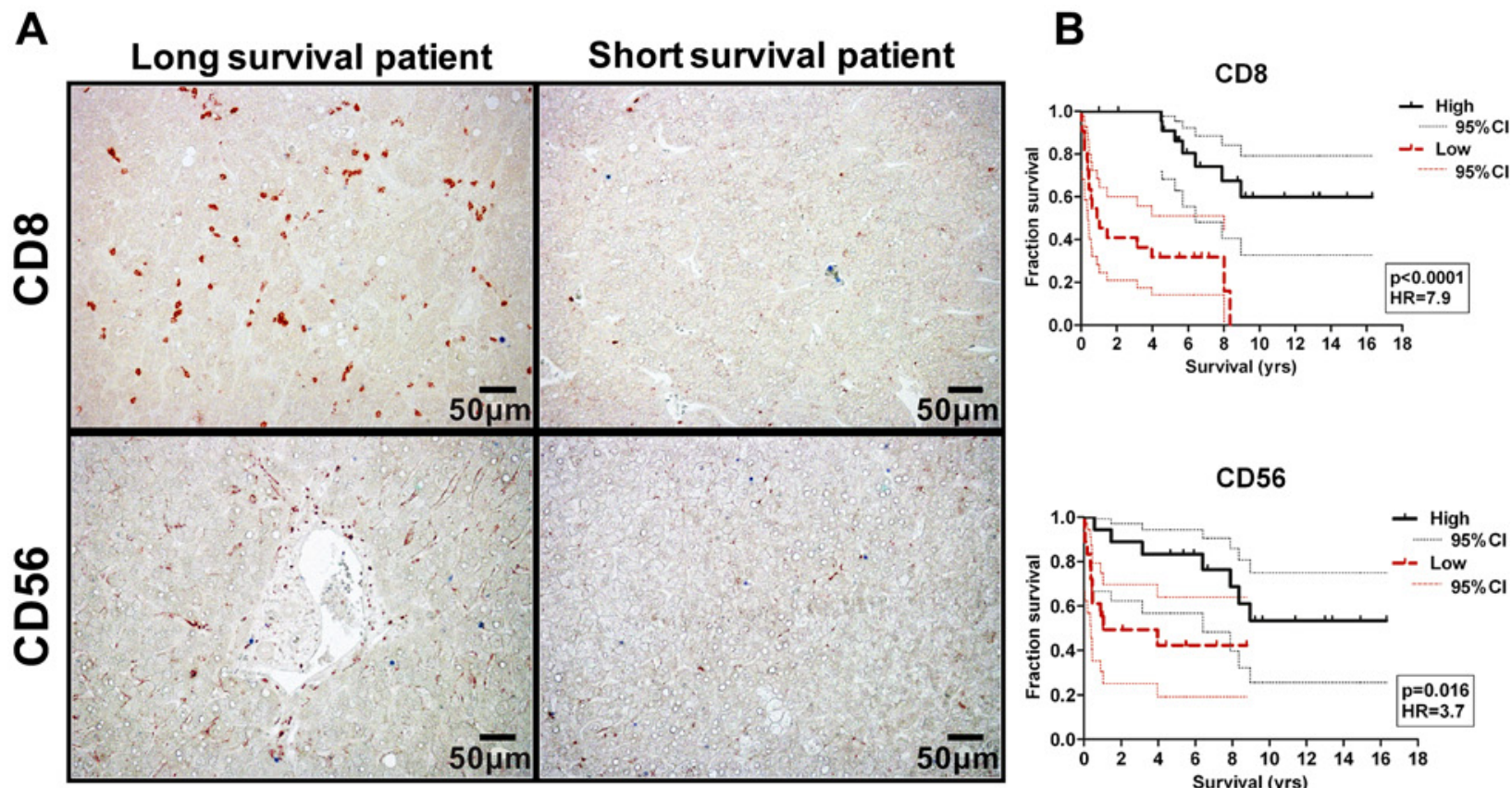

C

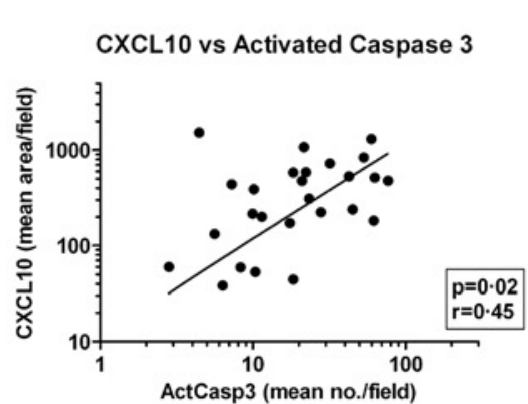

D
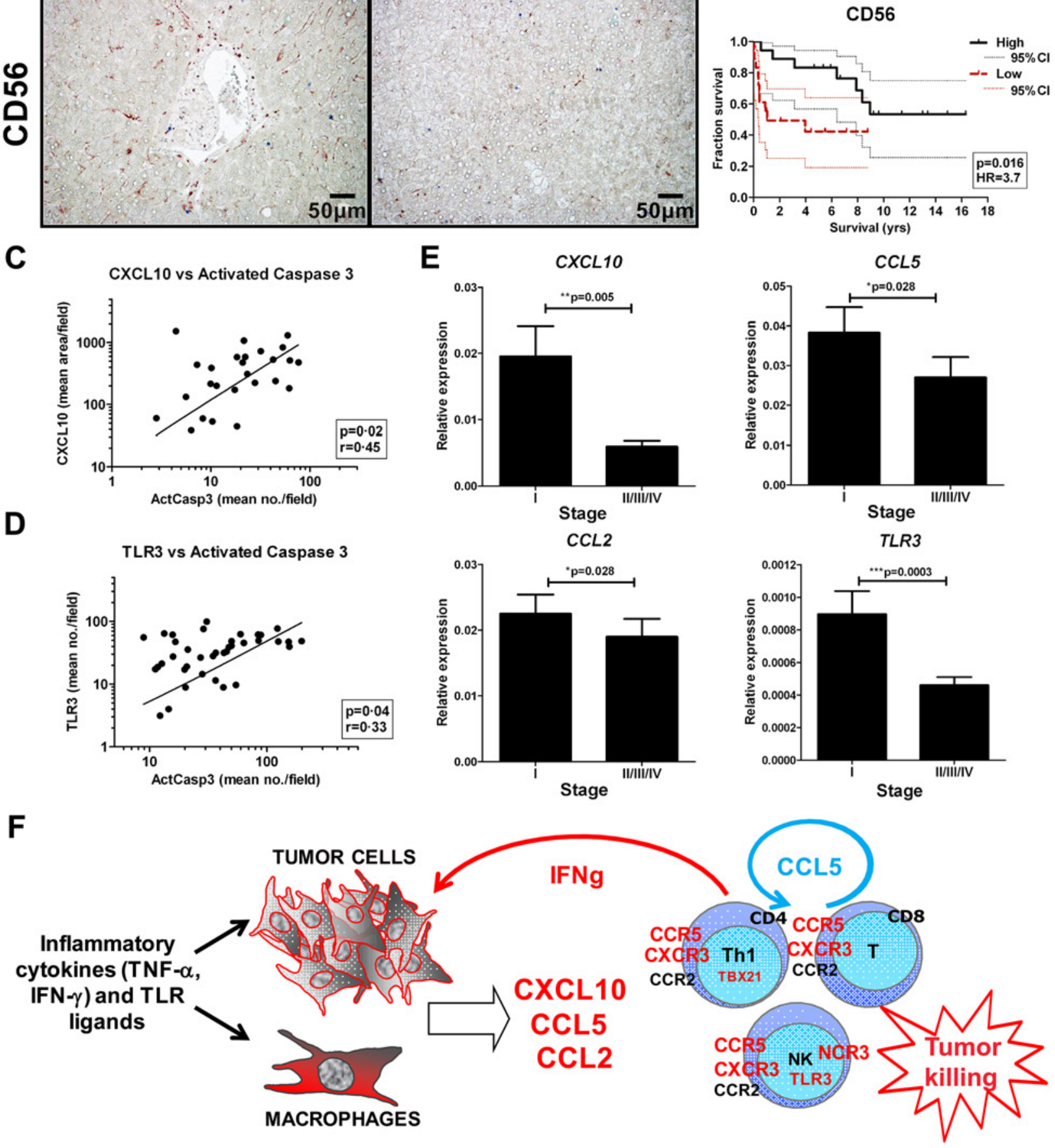

Figure 6 High chemokine expression levels, hence tumour infiltration by T and natural killer (NK) cells, are associated with superior patient survival. (A) Representative immunohistochemistry (IHC) images of CD8 and CD56 labelling (in red) showing higher density of CD8 ${ }^{+} \mathrm{T}$ and CD56 ${ }^{+} \mathrm{NK}$ cells in tumours from patients with longer survival (median survival $>3.9$ years). Bar $=50 \mu \mathrm{m} ; \times 200$ magnification. (B) Kaplan-Meier analysis showing that high density of intratumoural $\mathrm{CD}^{+}$and $\mathrm{CD}^{+} 6^{+}$immune cells is associated with superior patient survival. A subset of patients was chosen for immune 
We used the HCC cell line SNU-182 to address this question. SNU-182 cells were treated with IFN $\gamma$, TNF $\alpha$ and the TLR3 ligand poly(I:C) separately or in combination, and culture supernatants were analysed. While IFN $\gamma$ or TNF $\alpha$ alone had little effect, CXCL10 was strongly induced by the combination of IFN $\gamma$ and TNF $\alpha$ (figure $5 \mathrm{~A}$ ). Poly(I:C) alone significantly induced CXCL10 expression, and this effect was further enhanced by addition of IFN $\gamma$ (figure 5A). Poly(I:C) also induced CCL5 expression, while IFN $\gamma$ or TNF $\alpha$ alone or in combination had no detectable effect (figure 5B). All three factors induced CCL2 expression, but no synergistic effect was observed (figure 5C). Chemokine gene induction could be observed by qPCR already $6 \mathrm{~h}$ after treatment (data not shown).

To validate these observations in patient samples, we compared RNA expression of CXCL10, CCL5 and CCL2 and that of IFNG, TNF and TLR3 within tumours. Expression of the three chemokines correlated with that of IFNG, TNF and TLR3 $(\mathrm{n}=172$ patients from both the training and validation cohorts; figure 5D).

A transwell migration assay was performed using stimulated SNU-182 cells and healthy donor PBMCs. The induction of chemokines in stimulated SNU-182 cells induced transmigration of $\mathrm{T}$ (fivefold increase) and NK cells (2.5-fold increase), without affecting other leucocytes (data not shown). Transmigration of $\mathrm{T}$ and NK cells was abolished when PBMCs were pretreated with anti-CXCR3 (CXCL10) or anti-CCR5 (CCL5) neutralising antibodies (figure $5 \mathrm{E}$ ).

Taken together, these data indicate that IFN $\gamma, \operatorname{TNF} \alpha$ and TLR3 ligands are potent inducers of the survival-associated chemokines CXCL10, CCL5 and CCL2. These chemokines attract $\mathrm{T}$ and $\mathrm{NK}$ cells which, upon activation, produce more IFN $\gamma$, triggering a paracrine loop leading to further amplification of chemokine production and lymphocyte infiltration.

\section{Lymphocyte-attracting chemokines are associated with enhanced cancer cell death}

CD8A and NCR3, two genes specific for $\mathrm{CD}^{+} \mathrm{T}$ cells and $\mathrm{NK}$ cells, respectively, are present in our gene signature and globally more expressed in long-term survivors. This is indeed reflected by enhanced infiltration of $\mathrm{CD} 8^{+} \mathrm{T}$ and $\mathrm{CD} 56^{+} \mathrm{NK}$ cells within the tumour samples from patients with longer survival (figure $6 \mathrm{~A}$, a subset of patients chosen for validation $n=36$ or 46 ). Kaplan-Meier analyses showed that a higher density of infiltrating $\mathrm{CD}^{+} \mathrm{T}(\mathrm{n}=46, \mathrm{p}<0.0001, \mathrm{HR}=7.9)$ and $\mathrm{CD}^{+} 6^{+} \mathrm{NK}$ cells $(\mathrm{n}=36, \mathrm{p}=0.016, \mathrm{HR}=3.7)$ correlated with patient survival (figure 6B). Importantly, this was not observed for $\mathrm{CD}^{+} 8^{+}$ macrophages (Supplementary figure 4). In this subset of patients, the current immune signature was superior at predicting patient survival compared with tumour infiltration by T cells or NK cells.

We previously reported that the density of $\mathrm{CD}^{+} \mathrm{T}$ cells and $\mathrm{CD}^{+} 6^{+} \mathrm{NK}$ cells in HCC tumours correlates with cancer cell apoptosis detected by activated caspase-3 staining. ${ }^{16}$ Since CXCL10 and TLR3 activation play a major role in recruiting these cells, we examined if CXCL10 and TLR3 expression correlates with cancer cell apoptosis. Indeed, protein expression of CXCL10 ( $n=26, p=0.02, r=0.45$; figure $6 C)$ and TLR3 $(n=39$, $p=0.04, r=0.33$; figure 6D), an important inducer of CXCL10, CCL5 and CCL2, correlated with activated caspase-3 expression in cancer cells. Taken together, these correlations suggest a model in which chemokines expressed by cancer cells recruit lymphocytes that kill cancer cells, thereby contributing to prolonged patient survival. Such a model would predict that during the course of disease progression, cancer cells with reduced chemokines and TLR3 expression will be selected. Indeed, tumours from patients with more advanced HCC (stages II-IV; $\mathrm{n}=114$ ) exhibit significantly lower RNA expression of CXCL10, CCL5, CCL2 and TLR3 than those from stage I patients $(n=57)$ (figure $6 \mathrm{E})$. This further confirms the crucial role of chemokines in shaping a protective immune environment early in disease development.

\section{DISCUSSION}

In the present study we identified an immune signature which predicts the survival in resectable HCC irrespective of patient ethnicity or disease aetiology. Interestingly, it predicts the survival of early-stage patients for whom classical clinical parameters provide limited or no survival information. This signature, derived from resected HCC, comprises 14 genes coding for chemokines, inflammatory cytokines and lymphocyte markers. By combining transcriptome analysis, in situ staining and in vitro experiments, we identified regulatory circuits that shape and maintain a protective immune milieu within the tumour, leading to prolonged patient survival (figure 6F).

The immune signature was derived and tested using Singaporean patients and further validated in an independent cohort from Hong Kong and Zurich. The predictive value of the signature was also verified separately in various subgroups of patients (figure 2E). This consistency across different subsets of patients indicates that immune parameters determining disease progression are conserved irrespective of HCC heterogeneity. This is remarkable since HCC is known to be derived from multiple cell types (including hepatocytes or adult stem/progenitor cells) ${ }^{23}$ and caused by several aetiologies. Therefore, molecular features derived from the intratumoural immune response may be of better prognostic value than those relying on cancer cell characteristics. The loss of predictive power in female patients might be explained by the known gender disparity in the risk for HCC which is linked to oestrogen-mediated inhibition of interleukin 6 (IL-6) ${ }^{2425}$ as IL6 is one of the genes in our signature.

Previously, several studies using genomic approaches identified gene signatures that stratify HCC patients according to clinical prognosis. $^{8-12}$ These signatures were derived either from the adjacent non-tumour tissue or from the tumour itself. Signatures derived from the adjacent tissues emphasise risk factors for developing de novo tumours and support the 'field defect' hypothesis. ${ }^{10}$ Interestingly, immune characteristics of the

\footnotetext{
Figure 6 (Continued)

cell quantification by IHC (CD8, $n=46$, median $=74$ cells per field; CD56, $n=36$, median $=42$ cells per field; training and validation cohort). $p$, log rank $p$ value. (C) CXCL10 ( $n=26)$ immunofluorescence and (D) Toll-like receptor 3 (TLR3) $(n=39)$ IHC staining area positively correlated with the density of activated caspase-3-positive tumour cells. r, Spearman (CXCL10) or Pearson (TLR3) correlation coefficient. (E) Downregulation of CXCL10, CCL5, CCL2 and TLR3 RNA expression in stages II-IV $(n=114)$ compared with stage I patients with hepatocellular carcinoma $(H C C)(n=57)$. Graphs show means and SEM. $p$ Values were calculated using two-tailed Mann-Whitney U test. ${ }^{*} p<0.05$; ${ }^{* *} p<0.01$; ${ }^{* *} p<0.001$. (F) Model showing that the inflammatory cytokines tumour necrosis factor $\alpha$ (TNF $\alpha$ ), interferon $\gamma$ (IFN $\gamma$ ) and Toll receptor-like (TLR) ligands stimulate cancer cells or macrophages to produce the key chemokines CXCL10, CCL5 and CCL2. These chemokines induce tumour infiltration by Thelper 1 (Th1), CD8 ${ }^{+} \mathrm{T}_{\text {and NK }}$ cells which induce cancer cell killing and tumour control. Positive feedback loops result from the production of IFN $\gamma$ by activated T or NK cells that further enhance CXCL10 production (red arrow) and CCL5 by activated T cells that can attract more T cells (blue arrow).
} 
adjacent liver tissues have also been shown to impact patient survival. ${ }^{10}$ On the other hand, signatures derived from the tumour itself focus on genes involved in proliferation and the cell cycle ${ }^{81126}$ or on the identity of tumour-initiating cells. ${ }^{27} 28$ The current study is the first to focus exclusively on immune genes expressed within the tumour, and to show that the HCC immune milieu has an impact on disease outcome.

It may seem paradoxical that inflammation, an established risk factor for developing HCC, could play a protective role in HCC progression. ${ }^{29} 30$ For instance, IL-6 and TNF $\alpha$ were shown to promote HCC tumourigenesis. ${ }^{31-33}$ However, we found that these two cytokines correlate with longer patient survival in the present study. The beneficial impact of an active immune response within the tumour microenvironment is well established for non-small cell lung cancer (NSCLC), ${ }^{34}$ colorectal cancer $^{35}{ }^{36}$ and other malignancies. ${ }^{37}$ IL-6 and IL-8 were also reported to have a protective role in human colon adenomas. ${ }^{38}$ Similarly, depending on the mouse model, nuclear factor- $\mathrm{KB}$ (NF$\kappa \mathrm{B})$, a major regulator of inflammation, suppresses or promotes HCC development. ${ }^{39} 40$ Additionally, expression of the same biomarker, for example, IL-6, in the serum or within the tumour may also reflect different biological processes. ${ }^{16} 41$ These apparent contradictions indicate that the effect of inflammation is context dependent and that the same cytokine may have opposite effects on HCC tumourigenesis and progression. ${ }^{42}$

In our model, inflammatory cytokines (TNF $\alpha$ and IFN $\gamma$ ) and TLR ligands (probably released from necrotic cells) induce chemokine expression within the tumour microenvironment. These chemokines (CXCL10, CCL5 and CCL2) could recruit immune cells, which display antitumour activity reflected by enhanced activated caspase-3 expression in cancer cells. Furthermore, infiltrating immune cells augment chemokine production (possibly through secretion of IFN $\gamma$ or TNF $\alpha$ upon activation ${ }^{43}$ ) or directly secrete chemokines (CCL5), further stabilising the protective immune microenvironment. Such paracrine or autocrine loops are typical of complex biological systems as they provide efficient ways of amplifying signals and maintaining a particular immune status. ${ }^{44}$ Interestingly, no single cell type or molecular cue plays a unique role in shaping the immune microenvironment. Chemokines are produced by both cancer cells and TILs, while IFN $\gamma$ is produced by Th1 and NK cells. Such redundancy also participates in the robustness of the protective environment, which has to be maintained for years in order to impact patient survival. The current immune signature predicts survival in patients in stages I and II but not in those in stages III and IV. This shows that a protective immune response has to be established early enough to be effective. Hence we propose that once the tumour has been established for prolonged periods of time, multiple layers of immune tolerance may prevent the efficacy of antitumour responses. ${ }^{45} 46$ It was therefore predictable and also shown in this study that cancer progression would be associated with downregulation of chemokines critically involved in the shaping of a protective immune microenvironment.

In summary, our study reveals extensive cross-talk between cancer cells and tumour-infiltrating immune cells in establishing a protective immune milieu able to delay HCC progression. Improved understanding of the molecular pathways leading to a protective immune microenvironment will help in the rational design of new therapeutic approaches for patients with HCC.

\section{Author affiliations}

${ }^{1}$ Singapore Immunology Network (SlgN), Agency for Science, Technology and Research (A*STAR), Biopolis, Singapore
${ }^{2}$ Department of Pathology, The University of Hong Kong, Queen Mary Hospital, Hong Kong, China

${ }^{3}$ State Key Laboratory for Liver Research, The University of Hong Kong, Hong Kong, China

${ }^{4}$ Department of Pathology, Singapore General Hospital, Singapore, Singapore

${ }^{5}$ Department of Clinical Pathology, University Hospital of Zurich, Zurich, Switzerland

${ }^{6}$ Department of Visceral and Transplantation Surgery, University Hospital of Zurich,

Zurich, Switzerland

${ }^{7}$ Department of Surgery, The University of Hong Kong, Queen Mary Hospital, Pokfulam, Hong Kong

${ }^{8}$ Department of Medical Oncology, National Cancer Centre, Singapore, Singapore

${ }^{9}$ Department of General Surgery, Singapore General Hospital, Singapore, Singapore

${ }^{10}$ Institute of Neuropathology, University Hospital of Zurich, Zurich, Switzerland

${ }^{11}$ Institute of Virology, Technical University München, München, Germany

${ }^{12}$ Helmholtz Zentrum München, Germany

Acknowledgements We wish to thank Professor Pierre-Alain Clavien from the University Hospital of Zurich for his provision of patient archives and information, Dr Peter Schraml for the provision of patient FFPE sections, Jay Tracy for preparation of RNA samples, and Yatanar Soe from the National Cancer Centre Singapore for co-ordinating the collection of fresh HCC tissues and patient blood samples. We thank Dr L. Robinson and J-L. Lebrun for manuscript editing, and B. Toh for help in figure preparation. IOLN is Loke Yew Professor in Pathology.

Funding This study was mainly funded by The Biomedical Sciences Institutes (BMSI), Agency for Science, Technology and Research (A*STAR), and partly funded by a Hong Kong Research Grants Council Collaborative Research Grant to IOLN (HKU 7/CRG/09).

\section{Competing interests None.}

Ethics approval This study was conducted with the approval of the respective Institutional Review Boards.

Contributors VC: study concept and design; acquisition of data; analysis and interpretation of data; drafting of the manuscript; critical revision of the manuscript for important intellectual content; statistical analysis. JC: study concept and design; acquisition of data; analysis and interpretation of data. DL/EL: acquisition of data; analysis and interpretation of data. JL/KHL/AW/KS/RTPP/HY/LLPJO: administrative, technical or material support. HCT/MH/IOLN: study concept and design; critical revision of the manuscript for important intellectual content; administrative, technica or material support. AN: study concept and design; acquisition of data; analysis and interpretation of data; critical revision of the manuscript for important intellectual content; statistical analysis; study supervision. J-PA: study concept and design; analysis and interpretation of data; drafting of the manuscript; critical revision of the manuscript for important intellectual content; statistical analysis; obtained funding; administrative, technical or material support; study supervision.

Provenance and peer review Not commissioned; externally peer reviewed.

\section{REFERENCES}

1. El-Serag HB. Epidemiology of hepatocellular carcinoma in USA. Hepatol Res 2007;37(Suppl 2):S88-94.

2. Parkin DM, Bray F, Ferlay J, et al. Global cancer statistics, 2002. CA Cancer J Clin 2005; 55:74-108

3. Siegel AB, Olsen SK, Magun A, et al. Sorafenib: where do we go from here? Hepatology 2010;52:360-9.

4. Llovet JM, Burroughs A, Bruix J. Hepatocellular carcinoma. Lancet 2003;362:1907-17.

5. Hoshida Y, Nijman SM, Kobayashi M, et al. Integrative transcriptome analysis reveals common molecular subclasses of human hepatocellular carcinoma. Cancer Res 2009;69:7385-92.

6. Zucman-Rossi J. Molecular classification of hepatocellular carcinoma. Dig Liver Dis 2010;42(Suppl 3):S235-41.

7. Schutte K, Bornschein J, Malfertheiner P. Hepatocellular carcinoma-epidemiological trends and risk factors. Dig Dis 2009:27:80-92.

8. Boyault S, Rickman DS, de Reynies A, et al. Transcriptome classification of HCC is related to gene alterations and to new therapeutic targets. Hepatology 2007:45:42-52.

9. Budhu A, Forgues $\mathrm{M}, \mathrm{Ye} \mathrm{OH}$, et al. Prediction of venous metastases, recurrence, and prognosis in hepatocellular carcinoma based on a unique immune response signature of the liver microenvironment. Cancer Cell 2006;10:99-111.

10. Hoshida $\mathbf{Y}$, Villanueva $A$, Kobayashi $M$, et al. Gene expression in fixed tissues and outcome in hepatocellular carcinoma. N Engl J Med 2008;359:1995-2004.

11. Lee JS, Chu IS, Heo J, et al. Classification and prediction of survival in hepatocellular carcinoma by gene expression profiling. Hepatology 2004;40:667-76.

12. Ye $\mathbf{0 H}$, Qin $L X$, Forgues $M$, et al. Predicting hepatitis B virus-positive metastatic hepatocellular carcinomas using gene expression profiling and supervised machine learning. Nat Med 2003;9:416-23.

13. Allavena $\mathbf{P}$, Sica $A$, Solinas $G$, et al. The inflammatory micro-environment in tumor progression: the role of tumor-associated macrophages. Crit Rev Oncol Hematol 2008;66:1-9. 
14. Sica A, Larghi P, Mancino A, et al. Macrophage polarization in tumour progression. Semin Cancer Biol 2008;18:349-55.

15. Pages F, Galon J, Dieu-Nosjean MC, et al. Immune infiltration in human tumors: a prognostic factor that should not be ignored. Oncogene 2010;29:1093-102.

16. Chew V, Tow C, Teo M, et al. Inflammatory tumour microenvironment is associated with superior survival in hepatocellular carcinoma patients. J Hepatol 2010:52:370-9.

17. Henderson AR. The bootstrap: a technique for data-driven statistics. Using computerintensive analyses to explore experimental data. Clin Chim Acta 2005;359:1-26.

18. Hoshida Y. Nearest template prediction: a single-sample-based flexible class prediction with confidence assessment. PLoS One 2010;5:e15543.

19. Shurin MR, Shurin GV, Lokshin A, et al. Intratumoral cytokines/chemokines/growth factors and tumor infiltrating dendritic cells: friends or enemies? Cancer Metastasis Rev 2006;25:333-56.

20. Bauermeister K, Burger M, Almanasreh N, et al. Distinct regulation of IL-8 and MCP-1 by LPS and interferon-gamma-treated human peritoneal macrophages. Nephrol Dial Transplant 1998;13:1412-19.

21. Marfaing-Koka A, Maravic M, Humbert M, et al. Contrasting effects of IL-4, IL-10 and corticosteroids on RANTES production by human monocytes. Int Immunol 1996;8:1587-94.

22. Oi XF, Kim DH, Yoon YS, et al. Essential involvement of cross-talk between IFNgamma and TNF-alpha in CXCL10 production in human THP-1 monocytes. J Cell Physiol 2009;220:690-7.

23. Lee JS, Heo J, Libbrecht L, et al. A novel prognostic subtype of human hepatocellular carcinoma derived from hepatic progenitor cells. Nat Med 2006;12:410-16.

24. Naugler WE, Sakurai T, Kim S, et al. Gender disparity in liver cancer due to sex differences in MyD88-dependent IL-6 production. Science 2007:317:121-4.

25. Prieto J. Inflammation, HCC and sex: IL-6 in the centre of the triangle. J Hepatol 2008:48:380-1.

26. Chiang DY, Villanueva A, Hoshida $Y$, et al. Focal gains of VEGFA and molecular classification of hepatocellular carcinoma. Cancer Res 2008;68:6779-88.

27. Andersen JB, Loi R, Perra A, et al. Progenitor-derived hepatocellular carcinoma model in the rat. Hepatology 2010;51:1401-9.

28. Yamashita T, Ji J, Budhu A, et al. EpCAM-positive hepatocellular carcinoma cells are tumor-initiating cells with stem/progenitor cell features. Gastroenterology 2009;136:1012-24.

29. Marotta F, Vangieri B, Cecere A, et al. The pathogenesis of hepatocellular carcinoma is multifactorial event. Novel immunological treatment in prospect. Clin Ter 2004;155:187-99.

30. Matsuzaki K, Murata M, Yoshida K, et al. Chronic inflammation associated with hepatitis $C$ virus infection perturbs hepatic transforming growth factor beta signaling, promoting cirrhosis and hepatocellular carcinoma. Hepatology 2007;46:48-57.
31. He G, Karin M. NF-kappaB and STAT3 - key players in liver inflammation and cancer Cell Res 2011;21:159-68.

32. Wong VW, Yu J, Cheng AS, et al. High serum interleukin-6 level predicts future hepatocellular carcinoma development in patients with chronic hepatitis B. Int J Cancer 2009; 124:2766-70.

33. Wu JM, Xu Y, Skill NJ, et al. Autotaxin expression and its connection with the TNF-alpha-NF-kappaB axis in human hepatocellular carcinoma. Mol Cancer 2010;9:71

34. Dieu-Nosjean MC, Antoine M, Danel C, et al. Long-term survival for patients with non-small-cell lung cancer with intratumoral lymphoid structures. J Clin Oncol 2008;26:4410-17.

35. Ohtani H. Focus on TILs: prognostic significance of tumor infiltrating lymphocytes in human colorectal cancer. Cancer Immun 2007;7:4.

36. Galon J, Costes A, Sanchez-Cabo F, et al. Type, density, and location of immune cells within human colorectal tumors predict clinical outcome. Science 2006;313:1960-4.

37. Zitvogel L, Apetoh L, Ghiringhelli F, et al. The anticancer immune response: indispensable for therapeutic success? J Clin Invest 2008;118:1991-2001.

38. Kuilman T, Michaloglou C, Vredeveld LC, et al. Oncogene-induced senescence relayed by an interleukin-dependent inflammatory network. Cell 2008;133:1019-31

39. Maeda S, Kamata H, Luo JL, et al. IKKbeta couples hepatocyte death to cytokinedriven compensatory proliferation that promotes chemical hepatocarcinogenesis. Cell 2005; 121:977-90.

40. Pikarsky E, Porat RM, Stein I, et al. NF-kappaB functions as a tumour promoter in inflammation-associated cancer. Nature 2004:431:461-6.

41. Chau GY, Wu CW, Lui WY, et al. Serum interleukin-10 but not interleukin-6 is related to clinical outcome in patients with resectable hepatocellular carcinoma. Ann Surg 2000;231:552-8

42. de Visser KE, Eichten A, Coussens LM. Paradoxical roles of the immune system during cancer development. Nat Rev Cancer 2006;6:24-37.

43. Doherty DG, Norris S, Madrigal-Estebas L, et al. The human liver contains multiple populations of NK cells, T cells, and CD3 + CD56 + natural T cells with distinct cytotoxic activities and Th1, Th2, and Th0 cytokine secretion patterns. J Immunol 1999;163:2314-21.

44. Kitano H. Biological robustness. Nat Rev Genet 2004;5:826-37.

45. Bergmann C, Strauss L, Wang Y, et al. T regulatory type 1 cells in squamous cell carcinoma of the head and neck: mechanisms of suppression and expansion in advanced disease. Clin Cancer Res 2008;14:3706-15.

46. Zitvogel L, Tesniere A, Kroemer G. Cancer despite immunosurveillance: immunoselection and immunosubversion. Nat Rev Immunol 2006;6:715-27.

\section{Editor's quiz: GI snapshot}

\section{ANSWER}

From the question on page 401

Both gastric and colonic biopsies revealed eosinophilic material surrounding the capillaries and in the lamina propria and submucosa. This eosinophilic material stained positive for Congo red and showed apple green birefringence under polarised light, in keeping with amyloidosis. Immunohistochemical stain was negative for secondary amyloid. Primary (AL) amyloidosis was confirmed. A subsequent bone marrow biopsy confirmed the diagnosis of multiple myeloma.

Vomiting, diarrhoea and anorexia persisted and he failed to tolerate nasogastric feeding. Four weeks following admission he deteriorated, developing an acute abdomen with profound metabolic acidosis. An emergency laparotomy revealed diffuse ischaemia extending from the duodenojejunal flexure to the transverse colon. The mesenteric vessels were normal. Given the extensive nature of the ischaemia it was decided that conservative management would be the most appropriate option. Despite inotropic support on the intensive treatment unit he died 24 h later.

Over the course of his illness he displayed gastrointestinal haemorrhage, gastrointestinal dysmotility, pseudo-obstruction, and ultimately mesenteric ischaemia as a consequence of amyloidosis.

The forms of amyloidosis include primary (AL), reactive or secondary (AA), dialysis- or $\beta 2$-microglobulin-related, familial
(ATTR) and the localised varieties of amyloidosis. The amyloid protein in AL amyloidosis results from fragments of monoclonal light chains. In $\mathrm{AL}$ amyloidosis gastrointestinal involvement affects between $1 \%$ and $8 \%$ of patients. ${ }^{1}$ The most common gastrointestinal problems are related to dysmotility, malabsorption and haemorrhage as a result of increased tissue friability. There may also be deposition of amyloid in the vesse walls, which can lead to mesenteric ischaemia, as in this case. ${ }^{2}$ Endoscopic appearances of amyloid include mucosal granularity, erosion, ulceration and polypoid lesions. ${ }^{3} 4$

Treatment is on a symptomatic basis as well as treating the underlying cause by suppressing light chain production. This may slow progression, although the prognosis is still poor, with a median survival of $<2$ years with conventional treatment. ${ }^{5}$

Gut 2012;61:438. doi:10.1136/gut.2010.225441

\section{REFERENCES}

1. Menke DM, Kyle RA, Fleming CR, et al. Symptomatic gastric amyloidosis in patients with primary systemic amyloidosis. Mayo Clin Proc 1993;68:763.

2. Gilat T, Spiro HM. Amyloidosis and the gut. Am J Dig Dis 1968:13:619-33.

3. Tada S, lida M, Iwashita A, et al. Endoscopic and biopsy findings of the upper Gl tract in patients with amyloidosis. Gastrointest Endosc 1990;36:10.

4. Bighi S, Trevisani L, Lupi L, et al. Amyloidosis of the gastric stump: radiographic and CT findings. Gastrointest Radiol 1990;15:197.

5. Rajkumar SV, Gertz MA. Advances in the treatment of amyloidosis. N Eng/ J Med 2007:356:2413-15. 